\title{
Distal Revascularization and Interval Ligation "DRIL" Procedure in Steal Syndrome Management in Hemodialysed Patients
}

\section{Walid M Gamal ${ }^{1 *}$, Mohamed Ibrahim² and Hesham Aboloyoun²}

${ }^{1}$ Department of Vascular Surgery, Qena University Hospital, South Valley University, Qena, Egypt

${ }^{2}$ Department of Vascular Surgery, Assiut University Hospital, Assiut University, Qena, Egypt

\begin{abstract}
Background: Steal syndrome complicates access in an increasing number of chronic renal failure (CRF) patients. Surgical procedures as (banding or fistula ligation) to manage this issue have proved to be entirely unsatisfactory because of loss of the recently created access through ligation or attempted salvage by increasing resistance within the fistula.
\end{abstract}

Objective: To determine the results of DRIL technique in treating steal syndrome in CRF patients.

Methods: A retrospective study (2015 to 2017) was conducted on 49 patients complaining of steal syndrome (out of 1200 CRF patients) with ages ranged from 35 to 71 years (mean=57 years) after obtaining written informed consent. Twenty nine patients were females $(59.1 \%)$ and $20(40.9 \%)$ were males. These subjects have undergone DRIL procedure in Vascular Surgery Departments, Qena and Assiut University Hospitals. Pre-procedural angiography was performed in most cases. Patient characters, risk factors, types of fistulae and indications for surgery were listed. The clinical outcomes of the procedure, Arteriovenous Access (AVA) and bypass graft patency were determined as well.

Results: The AVA, which led to steal syndrome, was proximally located in the arm (brachiocephalic in 14 , brachiobasilic in 14, and prosthetic brachio-axillary in the remaining 21 patients). Steal symptoms comprised hand ache, neurologic deficiency and gangrenous ulcerations. The procedure was technically effective in all subjects. Prompt and total pain release was accomplished in $43(87.7 \%)$ of the 49 patients. One patient (2\%) with gangrene later underwent transmetacarpal amputation. No patient required hand amputation. During follow-up (range $0.5 \pm$ 17 months) hemodialysis was carried out continuously using the AVA in 40 subjects. AVA thrombosis had happened in $8(16.3 \%)$ subjects only post DRIL. Significant difference was found between diabetes and occurrence of steal syndrome ( $p$ value $<0.05$ ) and between type of fistula (prosthetic AVF) and steal syndrome as well ( $p$ value $<0.05)$. Six subjects died from other causes not related to the performed procedure.

Conclusion: In certain subjects DRIL technique is a secure and efficient method to manage steal syndrome. AVA durability is not influenced by this procedure. Pre-operative angiography pre and post AVA manual compression is essential for adequate patients' selection in which benefit will be gained mostly by the performed procedure.

Keywords: Distal revascularization and interval ligation; Dialysis; Arterial steal; Hand ischemia

\section{Introduction}

As the number of patients requiring hemodialysis grows, complications relating to vascular access become more frequent. Although rare, ischemia of the hand resulting from steal syndrome could be seriously dampened and seen in about $5 \%$ of subjects with upper limb arteriovenous fistulae (AVF) [1]. Clinically relevant ischemic hand post hemodialysis access surgery is rare (1-4\%) in native AVF. Its occurrence is believed to rise with the ageing and expansion of the hemodialysis subjects [2]. Operative adverse effects post AVA access comprised swelling of the arm, hemorrhage, infection and dialysis access-associated steal syndrome (DASS). DASS is diagnosed by rest pain, motor or sensory deficit and ulcers or gangrene leading to amputation [3].

A variety of treatment strategies have been reported for DASS including fistula ligation, banding (i.e., flow-limiting strategies), bypass and proximalization of the arteriovenous anastomosis. The decision is dependent upon variable elements, comprising the symptoms severity, patient risk factors, and the potential usefulness of the AVA per se [4]. DRIL operation is deemed nowadays the procedure of preference for maintaining the AVA patency while managing steal symptoms $[5,6]$. It was declared that DRIL technique is a long lasting intervention for
DASS, and multiple series have reported perfect long-term try patency rates approaching $80 \%$ at 5 years [4,7-9].

\section{Patients and Methods}

Between January 2015 and January 2017, DRIL operation was performed on 49 patients in Vascular Surgery Departments, Qena and Assiut University hospitals. Written informed consent was obtained from all participating subjects. Patient demographics and comorbidities were detected. Type of fistula whether (native brachiocephalic, upper arm basilic transposition, or synthetic graft) were listed.

The procedure's indications were classified into 4 classes: Emergence

*Corresponding author: Walid M Gamal, MD, Department of Vascular Surgery, Qena University Hospital, South Valley University, Qena-83523, Egypt, Tel: 0020882146543; E-mail: walidgamal@yahoo.com

Received August 23, 2017; Accepted September 13, 2017; Published September 22, 2017

Citation: Gamal WM, Ibrahim M, Aboloyoun H (2017) Distal Revascularization and Interval Ligation "DRIL" Procedure in Steal Syndrome Management in Hemodialysed Patients. J Vasc Med Surg 5: 336. doi: 10.4172/2329-6925.1000336

Copyright: @ 2017 Gamal WM, et al. This is an open-access article distributed under the terms of the Creative Commons Attribution License, which permits unrestricted use, distribution, and reproduction in any medium, provided the original author and source are credited. 
of ischemic rest pain, digital ulcers, limb gangrene and finally new neurological deficiency. Mild sensory neurological symptoms patients were excluded from the procedure. DRIL procedure was believed to be successful in treating rest pain if all symptoms were subsided; in treating digital amputation when healing was accomplished; and in managing a neurologic symptom if it was completely dealt with. Survival for a fistula was defined as the duration of its use prior to its abandonment as the primary method of achieving dialysis access.

The primary patency for a bypass graft was determined by clinical examination or duplex scan. Fistula salvage was determined as the period of its usage before its cessation as the initial way of accomplishing dialysis access and primary patency for a bypass graft was detected clinically or by duplex scan. Fistula failure within 6 months of DRIL was deemed to be an early loss and all other losses except those of 6 months duration were believed to be late.

\section{Inclusion criteria}

Patients had at least one of the following criteria beside the evident manifestations of ischemic hand: existence of reduced Doppler wave forms in both radial and ulnar arteries that enhanced with manual compression of the fistula; flow reversal in the brachial artery; peak velocities increase detected in both radial and ulnar arteries with fistula compression; or raised distal arterial flow with manual fistula compression detected on angiography. Adequacy of arterial inflow was investigated pre DRIL technique by duplex scan or arteriography. Most patients had preoperative extremity angiography for adequate patients' selection in which benefit will be gained mostly by the performed procedure (Figure 1).

A stenosis more than $50 \%$ was believed to be hemodynamically remarkable. Surveillance was performed at 1, 3, 6, 12 months and then each 6 months thereafter. Additional scans and/or managements were carried out for repeated hand manifestations, and/or considerable reductions in arterial pressures (i.e., $15 \mathrm{mmHg}$ drop in wrist pressure).

\section{Exclusion criteria}

Subjects with upper arm peripheral arterial disease discovered in preoperative angiography neither those with previous performed accesses and we used only great saphenous vein $(\geq 3 \mathrm{~mm})$ as a conduit and other graft types are excluded.

\section{Operative procedure}

When available, hemodialysis is done on the preceding day of the
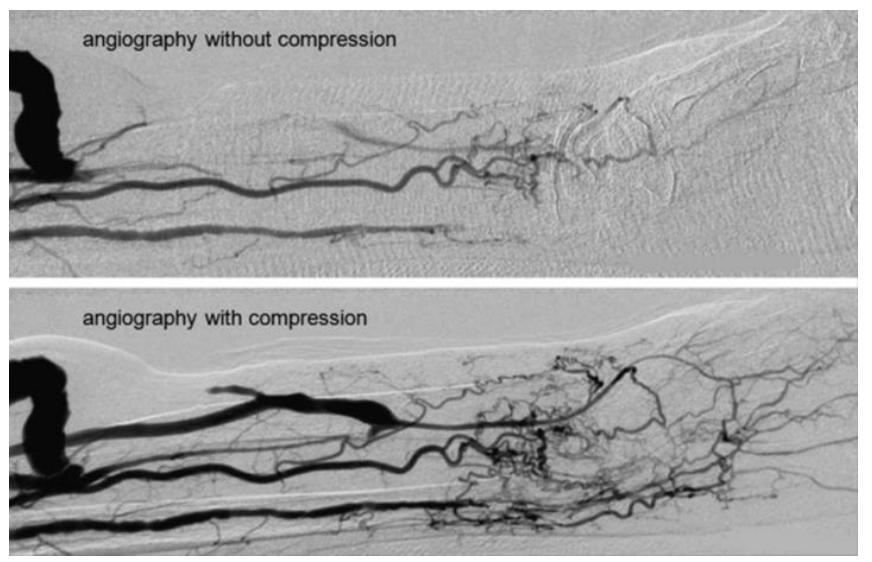

Figure 1: Arm angiography showing the pre-operative situation before and after compression of the shunt [5]

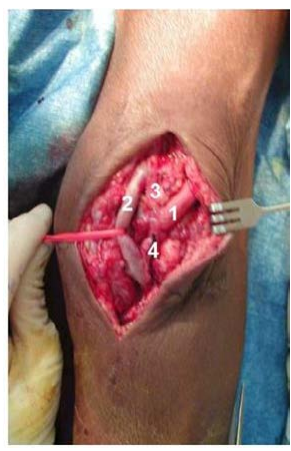

Figure 2: Distal revascularization by interposition saphenous vein graft and interval ligation of brachial artery where (1) is cephalic vein, (2) interposition saphenous vein graft, (3) Brachial artery just above anastomosis and (4) interval ligation of brachial artery just beyond the anastomosis of AVF.

surgery. Intravenous antibiotic was given about 30 minutes before surgery and general anesthesia was administered. The DRIL procedure was performed as follow; the proximal anastomosis of the vein graft bypass was created $\geq 7 \mathrm{~cm}$ proximal to the arteriovenous anastomosis of the access. The distal anastomosis was performed immediately distal to the access anastomosis and the brachial artery was ligated immediately proximal to the distal graft anastomosis. Our preferred graft was greater saphenous vein $(\geq 3 \mathrm{~mm})$. Post procedure, patients were given aspirin $(81 \mathrm{mg})$ unless contraindicated. Post procedure access and the vein bypass graft patency were assured by a palpable thrill and audible bruit existence over the AVA. Dialysis was continued accordingly on the next day using the current access (Figure 2).

\section{Statistical analysis}

All data were analyzed using SPSS version 15.0. Categorical variables were presented with percentages and frequencies. Student's $t$ test and chi square test were used to estimate differences between groups in risk factors and fistula types and steal syndrome occurrence. Time-to-event distributions for graft patency rates were estimated using Kaplan-Meier curves. The difference was considered statistically significant at $\mathrm{p}<0.05$.

\section{Results}

Between January 2015 and January 2017, 49 DRIL operations were carried out on 49 subjects with symptomatic steal syndrome. Twenty nine patients were females (59.1\%) and 20 subjects were males $(40.9 \%)$. Their ages ranged from 35 to 71 years (mean $=57$ years). Hypertension was present in $34.6 \%$ of patients, diabetes in $48.9 \%, 16.3 \%$ were smokers and 10 patients had ischemic heart disease (IHD). Fourteen DRIL operations were carried out after performance of a brachiocephalic fistula, 14 after a brachiobasilic fistula performance. Twenty one after a prosthetic bridge fistula creation and all prosthetic bridge fistulas were placed in the arm (Table 1).

Significant difference was found between diabetes as a risk factor and steal syndrome occurrence as "p value $<0.05$ " while there is no difference between other risk factors as hypertension, smoking and IHD and the occurrence of steal syndrome ( $p$ value $>0.05$ ). Statistically significant difference was found as well between type of fistula (prosthetic fistula) and steal syndrome happening as "p value $<0.05$ " but no significant differences with other types of fistula " $p$ value $>0.05$ " (Table 2).

Twenty six DRIL operations were carried out for ischemic hand 
Citation: Gamal WM, Ibrahim M, Aboloyoun H (2017) Distal Revascularization and Interval Ligation “DRIL" Procedure in Steal Syndrome Management in Hemodialysed Patients. J Vasc Med Surg 5: 336. doi: 10.4172/2329-6925.1000336

Page 3 of 5

\begin{tabular}{|l|c|c|}
\hline Variables & Number & Frequency \\
\hline Demographics & $57 \pm 10$ & \\
\hline Age, years (mean \pm SD) & \multicolumn{2}{|l|}{} \\
\hline Sex & 20 & 0.409 \\
\hline Male & 29 & 0.591 \\
\hline Female & \multicolumn{1}{|l|}{} \\
\hline Comorbidities & 17 & 0.346 \\
\hline Hypertension & 29 & 0.591 \\
\hline Diabetes & 10 & 0.204 \\
\hline IHD & 8 & 0.163 \\
\hline Smoking & 14 & 0.285 \\
\hline Type of fistula & 14 & 0.285 \\
\hline Brachiocephalic & 21 & 0.43 \\
\hline Brachiobasilic & & \\
\hline Prosthetic brachioaxillary & & \\
\hline
\end{tabular}

Table 1: Demographic data \& types of fistulae of the study subjects.

\begin{tabular}{|l|l|l|l|}
\hline Risk factors & $\begin{array}{l}\text { Steal Syndrome } \\
\text { (P Value) }\end{array}$ & Type of fistula & $\begin{array}{l}\text { Steal Syndrome } \\
\text { (P value) }\end{array}$ \\
\hline Hypertension & $>0.05(0.189)$ & Brachiocephalic & $>0.05(0.338)$ \\
\hline Diabetes & $<0.05(0.000)^{\star *}$ & Brachiobasilic & $>0.05(0.338)$ \\
\hline IHD & $>0.05(0.633)$ & Prosthetic brachioaxillary & $<0.05(0.002)^{\star *}$ \\
\hline Smoking & $>0.05(0.538)$ & brachioaxillary & - \\
\hline **"P value $<0.05$ is considered statistically significant". & \\
\hline
\end{tabular}

Table 2: Relations between risk factors, fistula type and steal syndrome occurrence.

\begin{tabular}{|l|c|c|}
\hline & Frequency & Percentage (\%) \\
\hline Ischemic pain & 26 & 53.2 \\
\hline Neurological deficit & 22 & 44.8 \\
\hline Gangrene & 1 & 2 \\
\hline Total & 49 & 100 \\
\hline
\end{tabular}

Table 3: Clinical presentation.

pain (53.2\%), 22 for neurological deficits (44.8\%), and the remaining case was presented by digital gangrene $(2.0 \%)$ (Table 2$)$. The median time to diagnosis of steal symptoms after access creation was 7 days for neurological deficits, 45 days for ischemic rest pain, 70 days for digital gangrene. Median time to develop steal manifestations was 30 days for those with prosthetic fistulas, 44 days for patients with brachiobasilic fistulas, and 58 days for those with brachiocephalic fistulas.

Post-procedural complications were reported in 11 patients (22.4\%); AVA thrombosis in 8 patients, mild hematoma in two subjects; treated by conservative means and follow up, and superficial infection occurred in one case and managed by local wound therapy. There were no perioperative deaths (Table 3 ).

Following DRIL, 43 patients had immediate and total pain relief, while improvement was not determined in the remaining 6 patients whom required later on ligation of the access. Distal pulses returned in 42 of the 43 patients. For the subject with preoperative gangrene, trans-metacarpal amputation of one finger was done later on (Table 4).

Mean follow-up period was 10.47 months (range 1-17 months). At the end of the follow-up duration 41 subjects had working AVA. Thrombosis of the access occurred in 8 patients 9 and 14 months after DRIL operation. During the follow up period the bypass graft was patent in 44 patients (89.7\%) and graft thrombosis was reported in the residual 5 cases (three of them had functioning AVA). Following DRIL procedure, adequate dialysis was maintained in all subjects on their regular basis (Figures 3 and 4) (Table 5).

\begin{tabular}{|l|c|c|}
\hline & Frequency & Percentage (\%) \\
\hline AVA thrombosis & 8 & 16.3 \\
\hline Infection & 1 & 2.04 \\
\hline Hematoma & 2 & 4.08 \\
\hline Total & 11 & 22.4 \\
\hline
\end{tabular}

Table 4: Post-procedural complications.

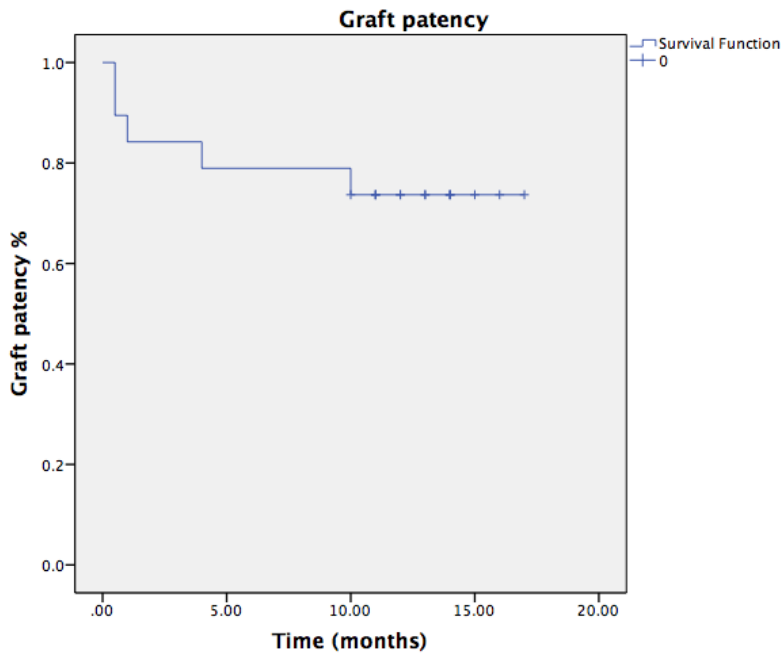

Figure 3: Kaplan-Meier curve showing graft patency.

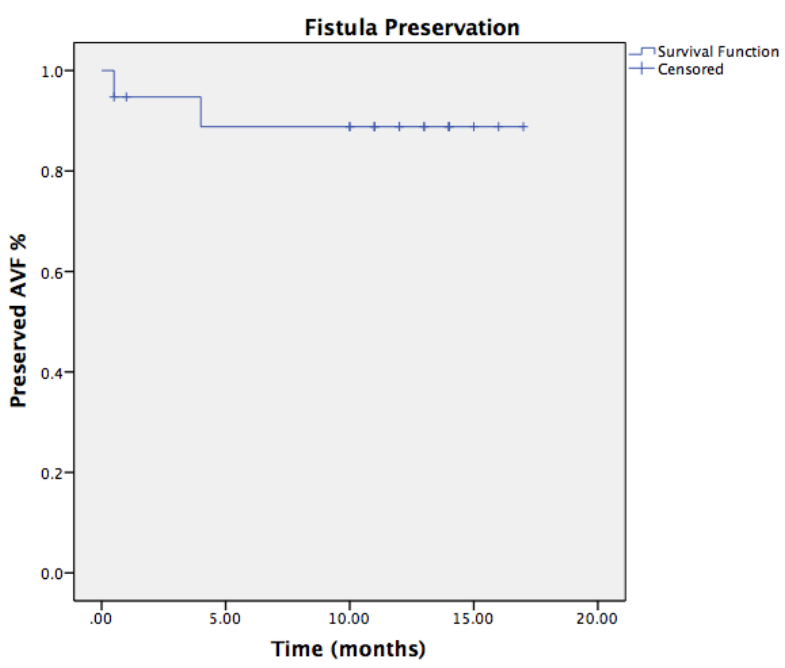

Figure 4: Kaplan-Meier curve demonstrating fistula preservation.

\begin{tabular}{|l|c|c|}
\hline & Frequency & Percentage (\%) \\
\hline No & 6 & 12.2 \\
\hline Yes & 43 & 87.8 \\
\hline Total & 49 & 100 \\
\hline
\end{tabular}

Table 5: Immediate improvement following manoeuver.

\section{Discussion}

It is well known that there are greater than 800,000 subjects in the United States had end-stage renal disease (ESRD) requiring dialysis [10]. With the rate of ESRD rising by about $15 \%$ yearly, the need for AVA will rise and a considerable assertion will be put on effective 
results post angio-access surgery [11]. Ischemic steal manifestations after fistula performance could be expensive in their management and important reason of subject morbidity as well. The total incidence of steal manifestations in our study was $4.08 \%$, which is comparable to that declared by other literatures [4,7]. When distal fistula compressing did not improve symptoms nor plethysmographic curves, ligation alone of the nonfunctioning AVF as well as proximalization or banding of the functioning AVF would have been inconvenient. The value of DRIL is dependent on how could it eliminates ischemic manifestations whilst maintaining patency of AVA [12].

DRIL substitutes one element of a large plan to diminish the hand ischemia incidence and avert its long-term outcomes. In comparison to some literatures [2], it is a prevalent issue and ought to be expected before surgery in particular categories of patients. The risk factors are extended and comprised old age, female sex, DM, peripheral arterial disease, large grafts (i.e., femoral/popliteal vein), and multiple prior procedures [13-16]. Furthermore, Gupta et al. reported that ischemic symptoms due to steal syndrome were more common in females and diabetics [12]. In accordance with previous studies, steal syndrome manifestations in our subjects occurred more in females (59.1\%) and in old aged patients and in diabetic patients more than non-diabetics We did not include subjects with upper limb peripheral arterial disease neither those with previous performed accesses and we used only great saphenous vein as a conduit $(\geq 3 \mathrm{~mm})$ as mentioned in exclusion criteria.

DRIL operation could be deemed as the preferred choice in steal syndrome patients. Although manual compression is a near-diagnostic test for the existence of the steal syndrome, the surgeon should always obtain a preoperative angiography of the entire arm before performing DRIL [7]. Such an angiography ought to be performed pre and post manual compressing of the AVA [17]. It will provide anatomic details regarding possible proximal and peri-access arterial stenosis and will also detail patency of the distal arterial tree. In this way the correct surgical approach could be performed [7]. If DRIL appeared to be the most appropriate therapy available, it had to be carried out at an early stage, preferably before digital gangrene develops or at least immediately after its appearance [18]. In contrast to previous study, in our subjects the median time of diagnosis of steal symptoms after access creation was 7 days for neurological deficits, 45 days for ischemic rest pain, 70 days for digital gangrene and this could be explained by late patient presentation to us with steal manifestations.

Regarding the type of AVF and its relation with the appearance of steal manifestations, in our study we could noticed that steal syndrome manifestations as acute neurologic deficits, ischemic wrist pain and even gangrene "that happened in one case with prosthetic graft" all appeared first and more with the prosthetic brachial-axillary access followed by brachiobasilic and cephalic accesses and this perhaps could be explained by the fact that larger diameters in prosthetic grafts compared to native AVF, which offers a low resistance pathway and less adaptation time for the body. Careful vessel selection for graft implantation and decision on arterial anastomosis size plays an important role to prevent steal. In general around $4 \mathrm{~mm}$ diameter arterial graft anastomosis would be good for AV graft using brachial inflow. When using a $6 \mathrm{~mm}$ ePTFE graft, there will be size discrepancy between the arteriotomy and the graft [19].

Moreover, the efficiency of DRIL is dependent on its capability to counter the hemodynamic alterations correlated to AVA performance. The construction of an AVA can cause a decrease in the arterial pressure and flow of blood beyond the AVA anastomosis. The normal compensatory responses include an increase in the cardiac output and arterial vasodilatation. When these compensatory responses are inappropriate, they may result in ischemic hand. A hemodynamically considerable lesion "either inflow or outflow" could aggravate the early hemodynamic alterations and furthermore prohibit the compensatory mechanisms [20]. Whilst, DRIL had more difficulties in comparison with other interventions as it implicated a vein established brachial artery bypass, DRIL resulted in excellent improvement of symptoms up to $87.7 \%$ in our work and is consistent with other large series (80\%$100 \%$ patient improvement) $[7,9]$.

Regarding graft patency following procedure, graft was patent in 44 patients $(89.7 \%)$ and graft thrombosis was reported in the residual 5 cases (10.2\%) (3 of them had functioning AVA) in our follow up period that extended up to 1.5 years. The prolonged bypass patency rates are expected since the relative brief extent of the graft as it involves a vein based brachial artery bypass and the adequate inflow. Many literatures had declared prolonged access patency following DRIL of $76 \%$ to $82 \%$ at 5 years $[8,21,22]$. Inspite of worries related to the demand of an axial artery ligation and limb dependence on an arterial bypass, several large series have found graft thrombosis as a rare condition, with 1ry patency of $86 \%$ to $100 \%$ at 1 year and $78 \% 65 \%$ to $96.9 \%$ at 5 years $[9,23]$.

In this study, the DRIL procedure was extremely successful in treating ischemic pain, digital ulcers, and finger gangrene, completely relieving symptoms in more than $80 \%$ of patients.

Limitations of the study: First is the retrospective nature of the study, second is the small sample size of the studied subjects so we could not suggest recommendations that could be applied on those particular patients. Third, our follow up period was quite short in comparison to other series but it is often hard to persuade the patients to adhere to the follow up program. Lastly, the accesses long-term patency and durability are not well recorded since mostly accesses thorough handling and observation is the responsibility of the nephrologists after being appropriate for dialysis.

\section{Conclusion}

DRIL technique is efficient in relieving steal manifestations post AVA creation while preserving the access function. It can be advocated as the initial management for CRF patients with ischemic pain, digital ulcers or finger gangrene with an expected good prognosis. Our results suggest that DRIL bypasses are durable despite the fact that long term results should be investigated.

\section{References}

1. Schanzer H, Skladany M, Haimov M (1992) Treatment of angioaccess-induced ischemia by revascularization. J Vasc Surg 16: 861-866.

2. Tordoir JH, Dammers R, Van der Sande FM (2004) Upper extremity ischemia and hemodialysis vascular access. Eur J Vasc Endovasc Surg 27: 1-5.

3. Collins AJ, Foley RN, Herzog C, Chavers B, Gilbertson D, et al. (2011) US Renal Data System 2010 Annual Data Report. Am J Kidney Dis 57: e1-e526.

4. Huber TS, Brown MP, Seeger JM, Lee WA (2008) Midterm outcome after the distal revascularization and interval ligation (DRIL) procedure. J Vasc Surg 48 926-932.

5. Scali ST, Huber TS (2011) Treatment strategies for access-related hand ischemia. Semin Vasc Surg 24: 128-136.

6. Mickley V (2008) Steal syndromeestrategies to preserve vascular access and extremity. Nephrol Dial Transplant 23: 19-24.

7. Knox RC, Berman SS, Hughes JD, Gentile AT, Mills JL (2002) Dista revascularization-interval ligation: a durable and effective treatment fo ischemic steal syndrome after hemodialysis access. J Vasc Surg 36: 250-255. 
Citation: Gamal WM, Ibrahim M, Aboloyoun H (2017) Distal Revascularization and Interval Ligation “DRIL" Procedure in Steal Syndrome Management in Hemodialysed Patients. J Vasc Med Surg 5: 336. doi: 10.4172/2329-6925.1000336

8. Aimaq R, Katz SG (2013) Using distal revascularization with interval ligation as the primary treatment of hand ischemia after dialysis access creation. $\mathrm{J}$ Vasc Surg 57: 1073-1078

9. Scali ST, Chang CK, Raghinaru D, Daniels MJ, Beck AW, et al. (2013) Prediction of graft patency and mortality after distal revascularization and interval ligation for hemodialysis access-related hand ischemia. J Vasc Surg 57: 451-458.

10. National Kidney and Urologic Diseases Information Clearing house (2012) Kidney disease statistics for the United States. Bethesda (MD): Department of Health and Human Services.

11. Schild AF, Collier PS, Fuller JC (2010) Vascular access surgery: an emerging specialty. In: Cameron JL, Cameron AM editors. Current surgical therapy (10th edn.), Philadelphia: Mosby, pp: 861-867.

12. Gupta N, You TH, Konig G, Dillavou E, Leers SA, et al. (2011) Treatment strategies of arterial steal after arteriovenous access. J Vasc Surg 54: 162-167.

13. Suding PN, Wilson SE (2007) Strategies for management of ischemic steal syndrome. Semin Vasc Surg 20: 184-188.

14. Davidson D, Louridas G, Guzman R, Tanner J, Weighell W, et al. (2003) Steal syndrome complicating upper extremity hemoaccess procedures: incidence and risk factors. Can J Surg 46: 408-412.

15. Huber TS, Hirneise CM, Lee WA, Flynn TC, Seeger JM (2004) Outcome after autogenous brachial-axillary translocated superficial femoropopliteal vein hemodialysis access. J Vasc Surg 40: 311-318.
16. Valentine RJ, Bouch CW, Scott DJ, Li S, Jackson MR, et al. (2002) Do preoperative finger pressures predict early arterial steal in hemodialysis access patients? A prospective analysis. J Vasc Surg 36: 351-356.

17. Valji K, Hye RJ, Roberts AC, Oglevie SB, Ziegler T, Bookstein JJ (1995) Handischemia in patients with hemodialysis access grafts: angiographic diagnosis and treatment. Radiology 196: 697-701.

18. Yaeger RA, Moneta GL, Edwards JM, Landry GJ, Taylor LM, et al. (2002) Relationship of hemodialysisaccess to finger gangrene in patients with end stage renal disease. J Vasc Surg 36: 245-249.

19. Ho JP, Cho KJ, Ko PJ, Chu SY, Gopinathan A (2016) Practical Guide to Surgical and Endovascular Hemodialysis Access Management case based illustration. World Scientific, Beaverton.

20. Illig KA, Surowiec S, Shortell CK, Davies MG, Rhodes JM, et al. (2005) Hemodynamics of distal revascularization-interval ligation. Ann Vasc Surg 19: 199-207.

21. Schanzer H, Skladany M, Haimov M (1992) Treatment of angioaccess induced ischemia by revascularization. J Vasc Surg 16: 861-864.

22. Berman SS, Gentile AT, Glickman MH, Mills JL, Hurwitz RL, et al. (1997) Distal revascularization-interval ligation for limb salvage and maintenance of dialysis access in ischemic steal syndrome. J Vasc Surg 26: 393-404.

23. Leake AE, Winger DG, Leers SA, Gupta N, Dillavou D (2015) Management and outcomes of dialysis access-associated steal syndrome. J Vasc Surg 61 754-760. 